\title{
Erratum to: Nicotinic Modulation of Innate Immune Pathways Via $\alpha 7$ Nicotinic Acetylcholine Receptor
}

\author{
Wen-Yan Cui $•$ Ming D. Li
}

Published online: 5 June 2010

(C) Springer Science+Business Media, LLC 2010

\section{Erratum to: J Neuroimmune Pharmacol}

\section{DOI 10.1007/s11481-010-9210-2}

In the recent article 'Nicotine modulation of innate immune pathways via $\alpha 7$ nicotine acetylcholine receptor', published online on April 13, 2010 in the Journal of Neuroimmune Pharmacology, errors appeared in Fig. 3a, b regarding the regulation of IKK $\varepsilon$ and TBK1 by TLR3. These two genes were regulated through TRIF. Please refer to the next page for the corrected figure.

The online version of the original article can be found under http://dx. doi.org/10.1007/s11481-010-9210-2.

W.-Y. Cui · M. D. Li ( $\bowtie)$

Department of Psychiatry and Neurobehavioral Sciences,

University of Virginia,

1670 Discovery Drive, Suite 110,

Charlottesville, VA 22911, USA

e-mail: Ming_Li@virginia.edu 


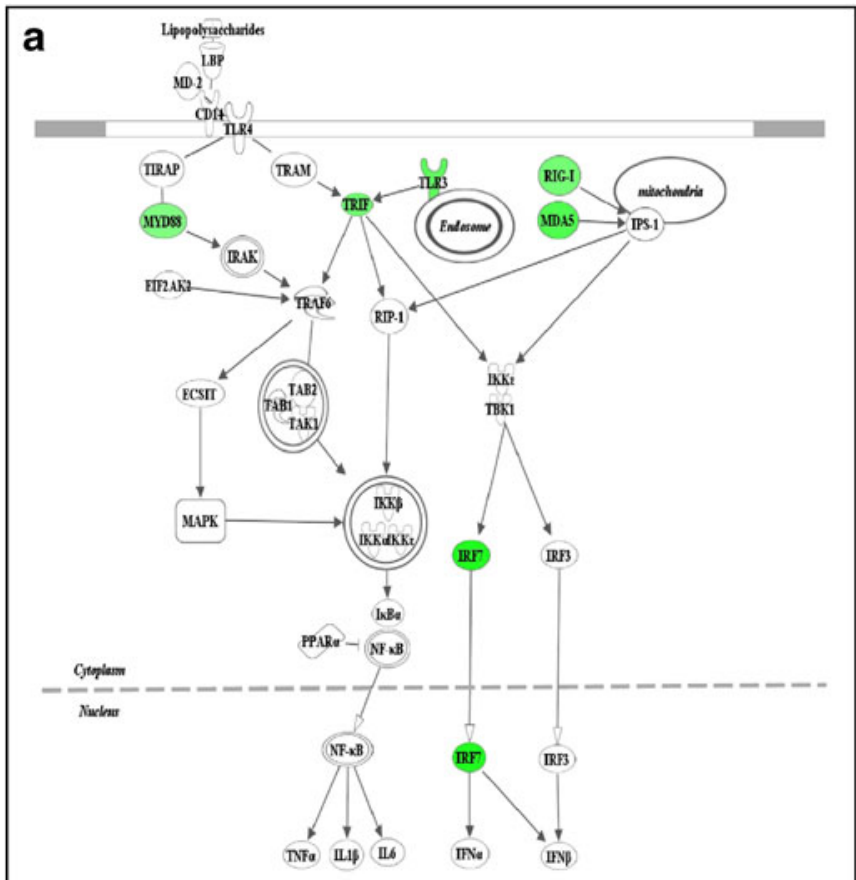

Fig. 3 Nicotine's effect on TLR pathways. a As a ligand for TLR4, LPS can trigger both MyD88- and TRIF-dependent pathways, leading to activation of $\mathrm{NF}-\mathrm{KB}$, which is responsible for the transcription of various pro-inflammatory cytokines and type I interferons (i.e., IRF3). The MyD88-dependent pathway is activated early, whereas the TRIF-dependent pathway is activated in the late phase. All the changes of RNA expression for more than 40 key and representative genes within the TLR4 pathway in RAW264.7 cells were measured by real-time RT-PCR after the cells had been stimulated

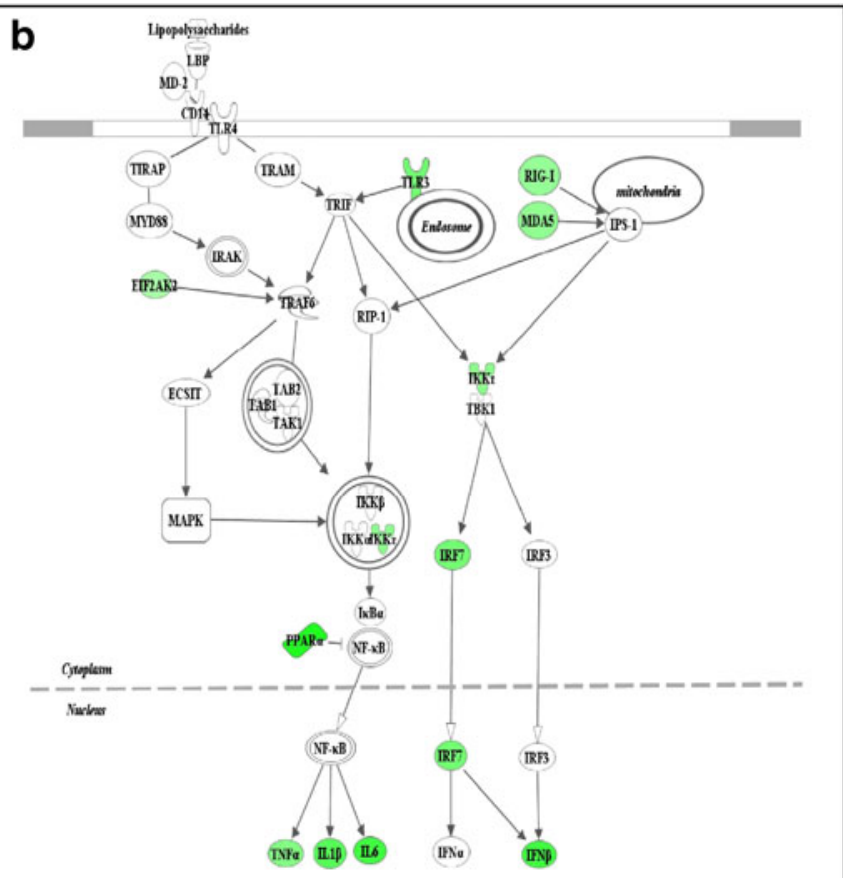

with LPS $100 \mathrm{ng} / \mathrm{ml}$ for $4 \mathrm{~h}$ with or without prior treatment with $5 \mu \mathrm{M}$ nicotine for $30 \mathrm{~min}$. b Poly(I:C) is a ligand for TLR3, triggering only the TRIF-dependent pathway. All results were obtained with RAW264.7 cells, which were stimulated with poly(I:C) $10 \mu \mathrm{g} / \mathrm{ml}$ for $16 \mathrm{~h}$ with or without prior treatment with $5 \mu \mathrm{M}$ nicotine for $30 \mathrm{~min}$. The genes significantly modulated by nicotine are indicated in green. The figures shown in $\mathbf{a}$ and $\mathbf{b}$ were constructed by Ingenuity Pathway Analysis software (www.ingenuity.com) with some modulations. 